\title{
13
}

\section{The implements of Lapita ceramic stamped ornamentation}

\author{
Wal Ambrose
}

\author{
Department of Archaeology and Natural History, \\ Research School of Pacific and Asian Studies, \\ The Australian National University, \\ Canberra ACT 0200, Australia \\ wra410@coombs.anu.edu.au
}

\section{Introduction}

Observers of early Lapita ceramic technology generally concede that the elaborately ornamented vessels were low-fired and made with un-standardised raw materials (Clough 1992:189; Intoh 1982:169), often including calcareous sand tempering from the prevalent use of beach sands in accord with the coastal setting of sites in the Bismarck Archipelago (Dickinson 2006:113). Both Clough and Intoh see the wide variation in pottery fabric and firing temperature as evidence of technological experimentation by potters faced with unfamiliar raw materials. Although the clay body was un-standardized in the sense that it used locally found raw materials, in contrast the decorated pottery is often self or red-slipped, producing a fine textured surface ideally suited to detailed decorative treatment, and differs from what Sand (1999a:146) refers to as an 'everyday ceramic' that was also produced within the same settlement region. The relative brevity of the notable Lapita ceramic tradition, once it spread beyond the Bismarck Archipelago (Anderson 2001), has been affirmed by Bedford's (2006:190) summary of developments in Vanuatu in the context of a wider presence in Remote Oceania of other short-lived Lapita ceramics. The localised production in widely dispersed settlements could provide an impetus for divergence from the superficially unified design. The transition from fastidious Lapita ornamentation on a wide range of vessel forms to more prosaic less varied pottery containers fashioned for different purposes signals the reduced importance of the emblematic appearance borne by the prepared pottery surface. The secularisation or re-working of founder emblems is part of the human colonising experience, but what seems less likely is the quick abandonment of a useful technology that was a feature of the art form's production, even 
while ceramics continued to be made. The loss of a technology that had a singular ability to produce such distinctive abstract and formal-figurative references may be a deliberate rejection of both the message and its linked medium as suggested by Siorat (1990).

\section{Lapita pottery as decorated artefact}

The implements fashioned for Lapita vessel ornamentation have not been found, nor were they carried forward to ornament later wares, but that they were especially fashioned for the purpose cannot be doubted. The loss of this art form technique is curious. Perhaps the labour-intensive stylistic emulation requiring special tools became too burdensome to descendent settlers with their increasing local social priorities. But as the technique was not similarly employed in decorating later wares it is more likely that it was as an inseparable part of the design's redundant message. Two to three centuries of strictly maintained decorative treatment within the Bismarck Archipelago passed before a century long eastward movement as far as Samoa occurred. There is evidence that the further the Lapita settlement was from the Bismarck Archipelago the faster became the transition to a plain ware (Kirch 2000:102), with the simultaneous loss of the stamping technology. Whatever the compulsion or allure that drove this dramatic eastward migration there remain the interesting questions of why the pottery was so elaborately ornamented, what social information it bore apart from being a cultural mnemonic, and what implements were used to produce it. The sudden appearance of the finely ornamented Lapita wares with its 'fullest flowering' (Best 2002:96) in the Bismarck Archipelago appears to be without an archaeologically visible antecedent (Bellwood 1997:234), either in expression as a developed art style, in the dentate stamping technique, or in the use of a non-standardised ceramic body as a base for the designs. A possible explanation for this would envisage a fusion of intrusive Austronesian and indigenous Papuan cultures as noted by Kirch (2000:93) following Green's (1991) Triple I model of Intrusion/ Innovation/ Integration. This would imply that a formal decorative system has been transferred from a pre-existing medium and applied to different materials using an innovative stamping technique. However, none of Green's distinctions (2000:374) for determining intrusive versus indigenous elements can explain the elaborate dentate stamped designs that appear fully developed on the first pottery in the Bismarck Archipelago. The model does not identify the inventors of the stamp technology or the origin of the designs apart from drawing an analogy with tattooing implements found at Lapita sites (Kirch 2000:105).

An alternative view consistent with Green's Triple I model focuses on the primary connection of both Lapita design and stamping technology that was originally confined within the Bismarck Archipelago. The attenuation of both these features away from the influence of a 'Bismarck Homeland' raises the question of Papuan input into the Lapita design elements and structural principles as are found in two-dimensional designs on arrow foreshafts from northern New Guinea (Craig 2005:505). Craig's thesis could help to explain the loss of a design repertoire as it moved away from the influence of a borrowed Papuan decorative art fashion in the Lapita 'homeland' area. This still leaves the sophisticated dentate stamping technology as an innovation confined to the Bismarck Archipelago.

Spriggs (1997:106) questions the appropriateness of 'Integration' in the Triple I model within the Bismarck Archipelago as a putative Lapita homeland by claiming that 'A local component is not denied but it may be relatively insignificant.' This view can be compared with that of Best (2002:50) that 'The invention of the roulette stamp is likely to have had significant and far-reaching effects on Lapita society... While the decoration itself is seen as part of a wider system, itself a response to some other social force, the (apparently) sudden appearance of these striking designs can only have had a reinforcing and intensifying effect on the society'. Whether or not the roulette wheel (see Figure 1) was reinvented, Best's claim for the importance of the designs and their florescence in 
tandem with the introduction of pottery is a serious observation. On the other hand such a strong claim for the use and importance of roulette stamps has lead Spriggs (2002:53) to extend this proposition to explain the lack of the Lapita design system in any developed form further west in Island Southeast Asia. Best (2002:46) cites several authors whose views were simply at the level of cursorily deciding whether or not a roulette was used, but having elevated the discussion to include wider social ramifications it is timely to examine this view by closer observation of the dentate stamped designs on Lapita pottery.

\section{Dentate stamping}

Apart from reasserting that Lapita pottery dentate stamping is an invention devised in the Bismarck Archipelago, this paper avoids further speculations surrounding the discussion of the 'why and whence' of the elaborate ornamentation and considers the more prosaic and accessible question of 'how'. Green's (1990:33) admonition against defining Lapita solely on the basis of the technology of dentate stamping has merit, but it should not exclude attention to the basic technology behind the ceramic's distinctive appearance. It appears that early in the ceramic's introduction its low-fired quality was accompanied by a prepared fine-textured surface produced to bear sophisticated dentate designs. There has been little detailed investigation of the dentate stamp as an artefact, but it could provide insights into the relative effort invested in producing the pottery as a measure of its social value. For example Siorat's approach in examining the irreducible elements of the art has led to a better understanding of the aesthetic basis of the design rules leading to the more integrated system proposed by Chiu and Sand (2005). As a welldeveloped complex design system that arose suddenly in the Bismarck Archipelago, and that suffered a decline as it extended eastwards, it clearly warrants analysis in its own right, as is normal with any other art/artefact analysis. This is the approach adopted in the detailed study by Best (2002) who has given the subject an important investigation at several levels, from the iconic clout the designs may have given to the colonising Lapita peoples, to the details of the pottery stamping tools used in the vessel's production.

Best has published a simulation using roulettes of a face image found on a Lapita ceramic (Best 2002:48), but the simulation fails to acknowledge that a wider range of stamp impressions was produced with a defined tool kit, such as that described by Siorat (1990). For example Siorat refers to the parabolic forms of the curved stamps, among others, a view confirmed by identifying the family of geometric curves commonly observed on sherds at the Malekolon site on Ambitle Island (Ambrose 1999). Best's study also makes a claim for the greater efficiency in time and effort in using a roulette stamp. If true this would be an important conclusion because it reduces the level of skill and devotion to detail that would otherwise be needed to produce the designs using repeated single stamps. It would therefore have an implication for the priority the society gave to the production of the elaborate designs. The suggested labour saving device of a roulette-applied design would devalue the importance of the pottery as an individual item compared with its slower production by more laborious use of single stamps.

\section{The stamp materials}

Some naturally occurring materials have been considered but rejected as ready-made stamps suited to produce the Lapita design corpus (Siorat 1990:60), such as the impressed ventral margin crenellation of various bivalve shellfish, occasionally recognized both in Lapita and later wares. Hollow sectioned bird bone could be used to make circular impressions while incised designs could be made with a multitude 
of pointed tools. The distinctive dentate stamping technology was a quite different matter requiring specially manufactured implements. Parallel examples are the multi-pronged bone tools found at Lapita sites that are matched by ethnographic examples of tattooing needles in bone (Poulsen 1987:207). Tattooing is a widespread human practice pre-dating any Lapita designs in the Bismarck Archipelago. The art of tattooing may be analogous to similar treatment of a prepared smooth pottery surface (Kirch 1997:131; 2000:105), but further understanding of any relationship between the implements for tattooing on skin and the tools for dentate stamping on pottery remains in the realm of conjecture. The dentate stamp impressions investigated in the Malekolon Lapita collection do not support a view that the same tools were used for tattooing purposes (Siorat 1990:60). This is clearly seen in the silicone moulds of the stamped designs in Figure 2, and for Lapita sherds from New Caledonia (Sand 1997:25), showing that the stamps had stumpy points or flat edges quite unsuited for penetrating skin, compared with the edge of bone tattooing implements that are straight and sharp (Poulsen 1987, Vol 2:185).

A novel claim for a fingernail sharpened to a saw-tooth edge as a dentate stamp has been suggested along with the use of a serrated end-rounded spatula to be used in a semi-roulette fashion (Basek 1993). The postulated use of these items to create the appearance of dentate stamped designs on Lapita wares has been eclipsed by Best's claim (2002:47) that a roulette was used in order to delineate not only design boundaries but most or all of the main designs. In order to test this most strongly claimed proposition a detailed inspection was made of sherds from the Malekolon site on Ambitle Island.

\section{The Malekolon Lapita Collection}

Although the Malekolon (EAQ) Ambitle site is disturbed, probably by flooding associated with a volcanic event around 2300 years ago, it contains Lapita style sherds from two excavated collections, the first accepted as an associated Far Western Lapita group that includes Eloaue and Talasea (Anson 1986:163),

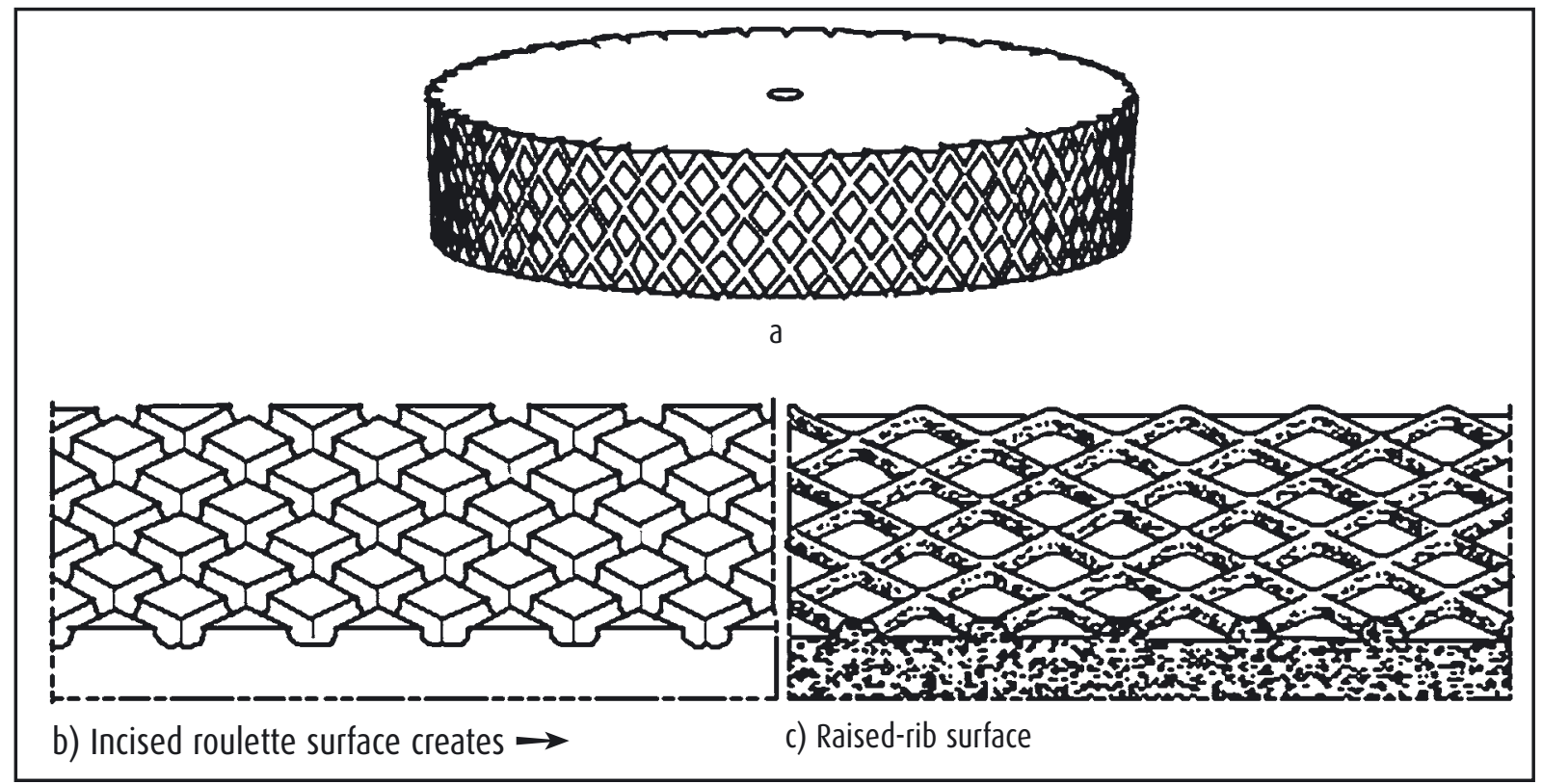

Figure 1. Hypothetical diagonally hatched incised roulette surface (a), and the implied grid form of ridges produced when applied to soft clay (b). None of the inspected sherds in the Malekolon collection has evidence of the raised ribs shown in (c) that a roulette would produce. 


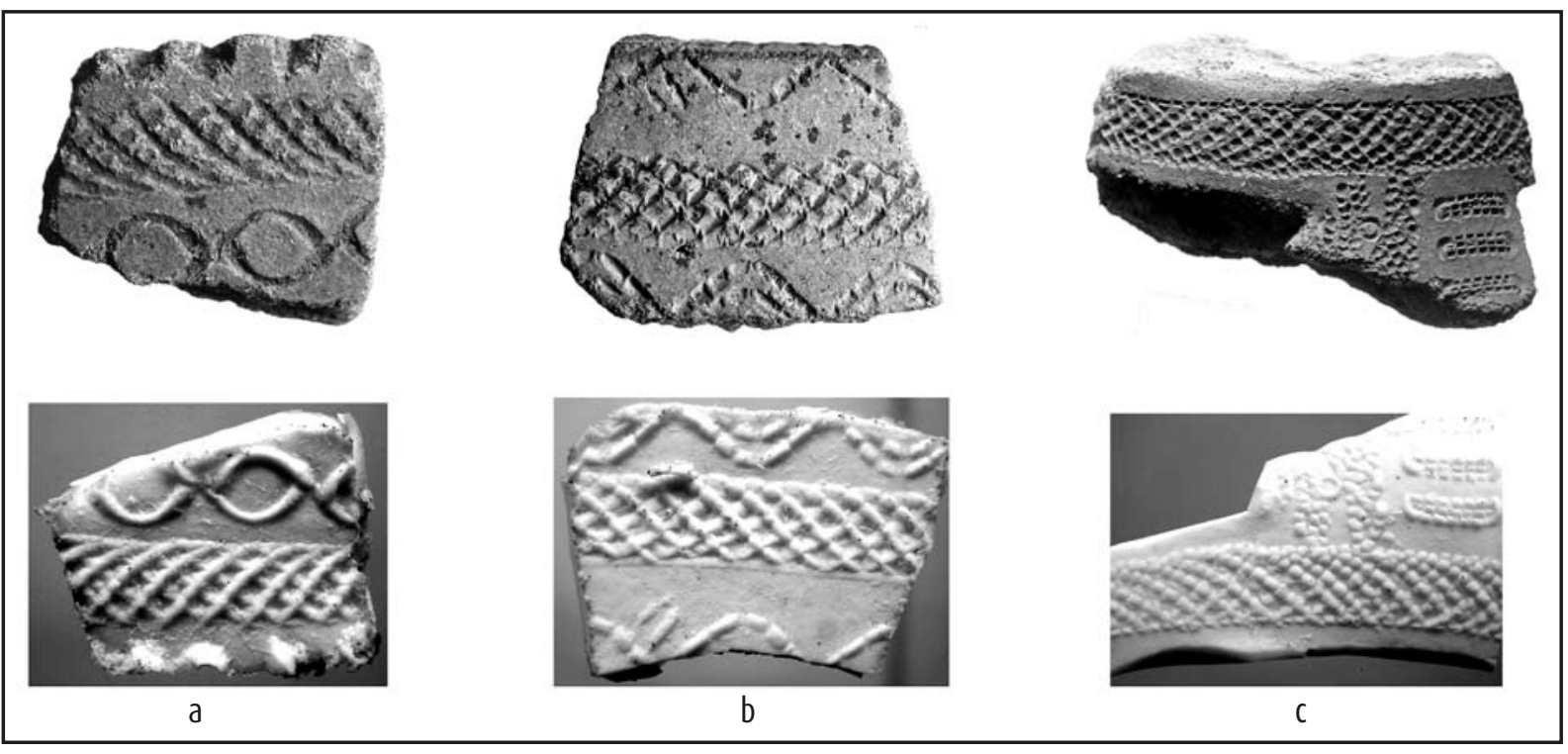

Figure 2. The top row of sherds show imprinted compound zone markers. The bottom row shows silicone moulds of these sherds. The mould surface clearly demonstrates repeating overlapping curved elements that form the wide ribbon units in the pottery. Sherd (a) is imprinted with plain curved stamps; sherd (b) has weakly developed dentate impressions; sherd (c) has more developed dentate stamp impressions, but all three share the same repeating technique. Each repeating stamp is sited on a previously drafted guideline. The sherd widths are (a) $22 \mathrm{~mm}$, (b) $34 \mathrm{~mm}$, (c) $48 \mathrm{~mm}$.

and the second ascribed to Middle Western Lapita (Summerhayes 2000:173). The Malekolon Lapita pottery therefore possesses a range of design characteristics found at many other sites. This paper reports the result of a macroscopic examination of all decorated sherds in the first Anson-studied Malekolon collection. Sand (1997:25) shows the same evidence with silicone casts of single stamp impressions from New Caledonian Lapita sherds. An examination of the hypothetical impressions produced by roulette, compared with the impressions actually found in the sherd collection helped to clarify the matter. The study failed to produce evidence of roulette use.

\section{Roulette and other impressions}

Consider the photograph by Best (2002:47, plate 2) of the surface of two roulette stamps produced by incising crossed diagonal lines as in Figure 1a to produce a wide parallel edge with raised quadrilateral tiles as illustrated in Figure 1b. Roulettes of this design would produce a grid pattern of tiled depressions separated by raised ribs in a soft material, as shown by the surface effect and cross section produced diagrammatically in Figure 1c. This result is not found in any of the examined Lapita dentate stamp sherds from the Malekolon collection contradicting the claim for roulette use, particularly as it refers to wide bands appearing as design zone boundaries in the overall vessel ornamentation.

The repetitious curved impressions and their geometric similarities have not been adequately considered in Best's presentation of the case for the use of roulettes. The wide-band zone boundaries that appear on the Malekolon sherds are all formed from a series of multiple curved or straight elements in plain and dentate form. An individual stamp can often be recognised in a band by its identical curvature and, where they occur, by the number of tines and slight unevenness in their spacing. In setting the design field layout a single guideline on the clay can sometimes be still observed. The draft line served to assist regular stamp alignment while providing a margin for the terminal ends of both the plain and dentate curved stamps in a carefully 


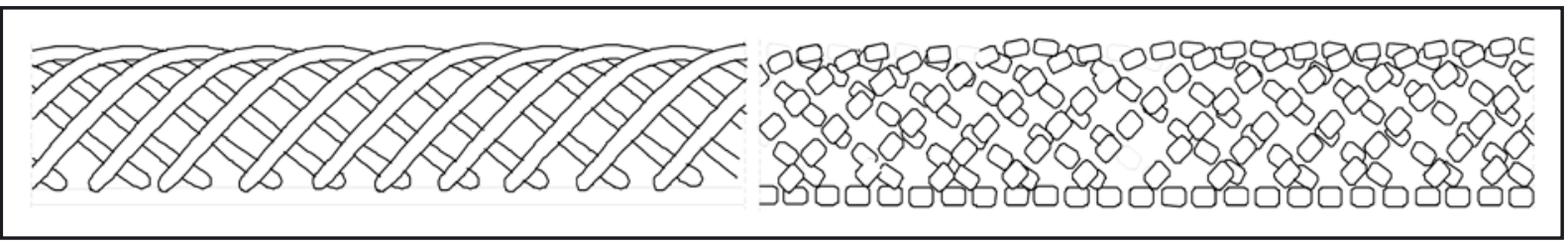

Figure 3. Unlike the raised rib band that would accompany the use of a continuous cross-hatched roulette, the evidence from the Malekolon collection is that a band was formed by repeated use of a single curved stamp as shown diagrammatically. The band can consist of repeated plain or dentate curves to produce the desired effect. Guidelines are found for the hanging arms of the repeating stamps that would otherwise leave a ragged edge, whereas the curve apices form their own continuous frieze margin.

controlled manner to produce the required zone boundary strips. This can be seen in the sherds and the silicone casts of these illustrated in Figure 2 where the overprinted trailing limb of each stamp impression is preserved to produce a wide band that could act as a design zone boundary. Figure 3 indicates diagrammatically how the basic curved elements that make up the graphic zone boundaries are created with repeated single stamps. There is clear evidence for the direction of stamping with multiple line zone markers when one trailing end of each curved stamp impression is overprinted.

a

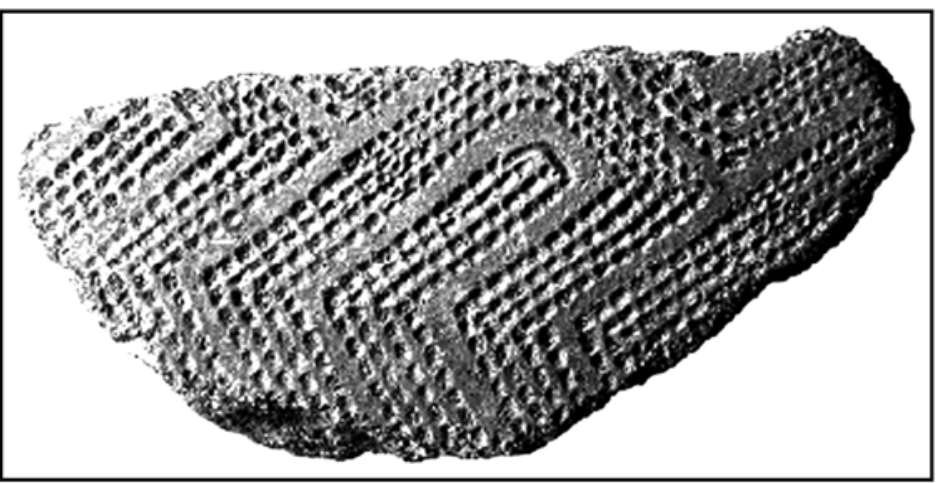

b

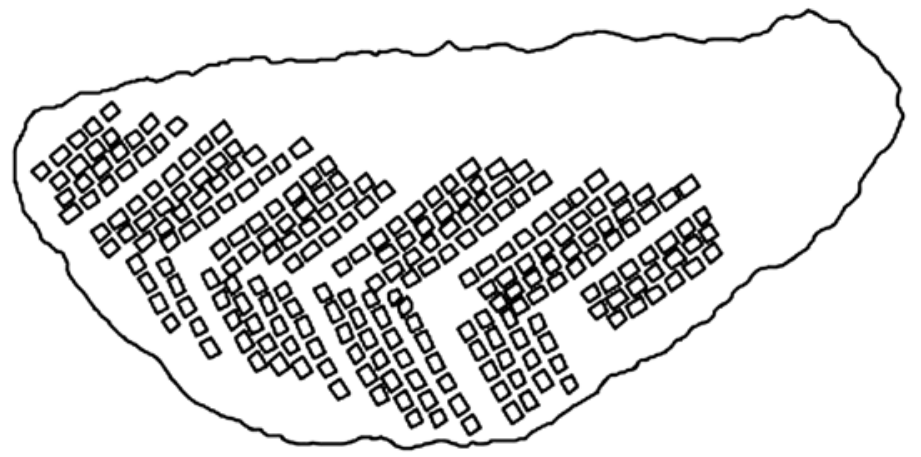

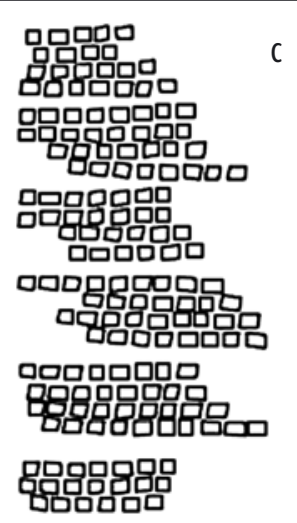

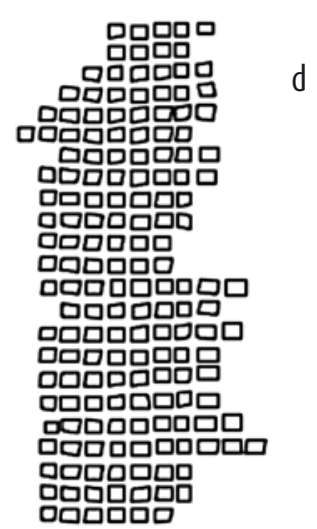

Figure 4. The sherd shown at (a) has the complex interlocking labyrinth design found as a design field on Lapita pottery from the Bismarck Archipelago to New Caledonia. A central zone has been abstracted as rectangular tine imprints shown in (b). The topmost course is realigned into a horizontal series at (c) where the semi-parallel stamp lines show the irregular nature of each four-line band. When the individual lines of $(c)$ are re-aligned as in $(d)$ it appears that a single stamp tool could produce all the features of the topmost stamp course. Another feature of the design appears to be that the stamped impressions are adjusted by crowding some lines in order to satisfy the complementary design requirements of the un-stamped areas. Overlapping stamp impressions have not been included in the diagram. The sherd width is $44 \mathrm{~mm}$. 
Straight dentate stamps are equally important in producing Lapita designs. The Lapita labyrinth design shown with extraordinary complexity on the well-preserved vessels excavated in New Caledonia (Sand 1999b:41-3) is a good example. Detailed inspection again provides no evidence that roulettes were used for any of the sherds in the Malekolon collection. As with the New Caledonian examples the complex interlocking angular labyrinth on the Malekolon sherd (Figure 4) would be particularly difficult to apply as a repeating two-dimensional geometric design to a three-dimensional curved surface area. The pottery surface preparation and draft outline would require careful execution to ensure that the complete design was applied with the symmetry expected in early Lapita pottery ornamentation. Three stamps appear to be employed on this single sherd, one straight with at least eleven tines, one curved with up to twenty tines, and another short, curved and plain. Overlapping areas can be seen where both the straight and curved stamps meet. The design that needed to be accommodated on the pottery surface is not simply produced by the stamped areas but also in the design of the blank zone between. In cases where it is possible to see the blank design it is clear that the dentate areas are sometimes crowded to allow the alternate blank areas to be seen in correct form. Figure 4 illustrates this feature when the dentate stamp area is slightly overprinted to produce a narrower zone of multiple lines. The illustrated sherd in Figure 5 (a) has sets of parallel dentate lines in the composition of the image. The two abstracted tine line sets in (b) are enlarged in (c) and (d) to clearly demonstrate that each line is offset, no doubt to fit the design requirement at the edge intersections of the lozenge-shaped central figure. The importance of

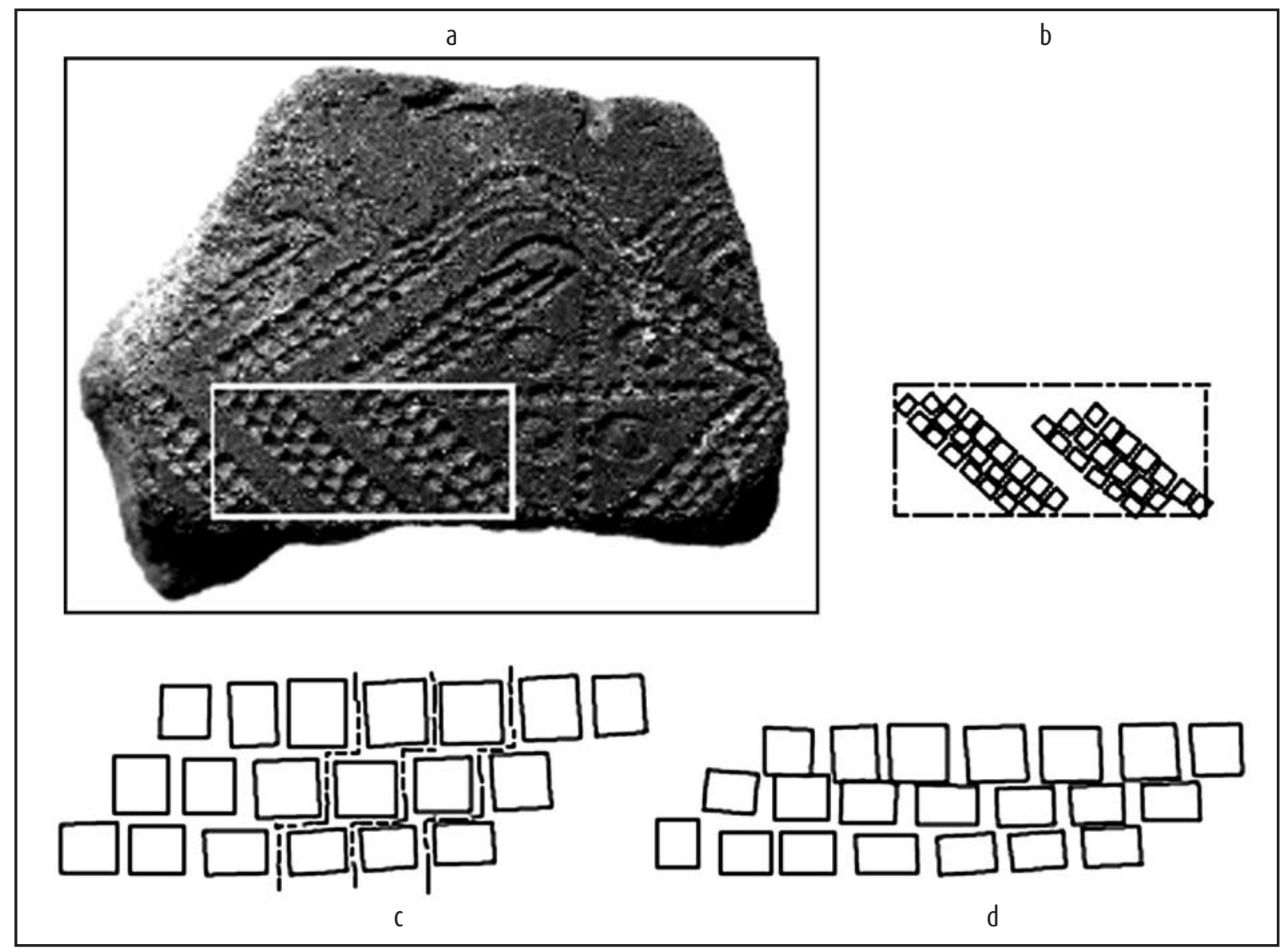

Figure 5. The offsets in individual stamp imprints show that multiple dentate lines were used to produce the composite image in (a). The extracted segments shown in (b) are enlarged in c and d. The offsets indicated by the dashed lines in (c) show that individual linear imprints are used to produce a wide frame for the enclosed design. In (d) there are lateral distortions that squeezed the repeated lines together, to produce a narrower design frame but allowing for equal width of the parallel plain zones. The sherd width is $30 \mathrm{~mm}$ while the top dentate course in (c) is $7.5 \mathrm{~mm}$. 
maintaining the width of the intervening non-dentate design has been observed by crowding the triple-line strip as seen in (d). Other sherds, not illustrated here, show that the negative image can take precedence by reducing the number of individual stamp lines in a multiple stamp band, from say four to three.

\section{Conclusion}

I have argued elsewhere that the material used to produce the stamping tools was readily available in the form of turtle shell, particularly from the hawksbill turtle Eretmochelys imbricata (Ambrose 1997, 1999). Turtle scute can be easily bent into a range of curves when it is heated to around $90^{\circ} \mathrm{C}$. Even so, in the case of the Malekolon collection there is a narrow range of curves closely matching the parabolic geometry of conic sections. Given the flexibility and relative plasticity of scute when heated, it is clear that the range of curves applied to the pottery has been limited to the simplest bent forms. Both the meticulous way in which the designs were applied, and the formal complexity of some of the design fields are evidence of strict design rules. Other possible linear marks made with stamping tools apart from the straight and single bent curves appear to be absent. Although there was close adherence by the potters to very constrained rules of design, within those limits they were able to achieve a remarkable visual complexity. A roulette was not used to assist quick application of the various designs emphasising the laborious task of producing such a wide corpus of work, often on large pottery vessels using only repeated single stamps. The imprinting of detailed patterns on clay vessels that needed to be kept semiplastic for an extended period while the work was done, and with often complex symmetry underlines the skill of the designers. This implies that an important social investment was made in the production of this ornamented pottery beyond any value that a utilitarian ware may have had.

\section{References}

Anderson, A. 2001. Mobility models of Lapita migration. In G.R. Clark, A.J. Anderson and T. Vunidilo (eds), The archaeology of Lapita dispersal in Oceania, pp.15-23. Canberra: Pandanus Books, Australian National University. Terra Australis 17.

Ambrose, W. R. 1997. Contradictions in Lapita pottery, a composite clone. Antiquity 71(273):525-538.

Ambrose, W. R. 1999. Curves, tines, scutes and Lapita ware. In J-C. Galipaud and I. Lilley (eds), Le Pacifique de 5000 à 2000 avant le present, pp. 119-126. Paris: Institut de Recherche pour le Développement.

Anson, D. 1986. Lapita pottery of the Bismarck Archipelago and its affinities. Archaeology in Oceania 21:157-65.

Bedford, S. 2006. Pieces of the Vanuatu Puzzle, Archaeology of the North, South and Centre. Canberra : Pandanus Books, Australian National University. Terra Australis 23.

Basek, M. 1993. A Lapita edge. BA (Hons) thesis. University of Sydney.

Bellwood, P. 1997. Prehistory of the Indo-Malaysian Archipelago. Honolulu: University of Hawai'i Press.

Best, S. 2002. Lapita: A view from the East. Auckland: New Zealand Archaeological Association Monograph 24.

Chiu, S. and C. Sand 2005. Recording of the Lapita motifs: proposal for a complete recording method. Archaeology in New Zealand, 48(2):133-150.

Clough, R. 1992. Firing temperatures and the analysis of Oceanic ceramics: a study of Lapita ceramics from Reef/ Santa Cruz, Solomon Islands. In J-C. Galipaud (ed), Poterie Lapita et Peuplement, pp 177-192. Nouméa: ORSTOM. 
Craig, B. 2005. What can material culture studies tell us about the past in New Guinea? In A. Pawley, R. Attenborough, J. Golson and R. Hide (eds), Papuan Pasts, cultural, linguistic and biological histories of Papua-speaking peoples, pp. 493-513. Canberra: Research School of Pacific and Asian Studies, Australian National University. Pacific Linguistics 572.

Dickinson, W.R. 2006. Temper sands in prehistoric Oceanian pottery. Special Paper 406, Boulder Colorado: The Geological Society of America.

Green, R. 1990. Lapita design analysis: the Mead system and its use; a potted history. In M. Spriggs (ed), Lapita Design, Form and Composition, pp. 33-52. Canberra: Dept of Prehistory, Australian National University. Occasional Papers in Prehistory 19.

Green, R. 1991. The Lapita Cultural Complex: Current Evidence and Proposed Models. Bulletin of the Indo-Pacific Prehistory Association 11(2):295-305.

Green, R. 2000. Lapita and the cultural model for intrusion, integration and innovation. In A. Anderson and T. Murray (eds), Australian Archaeologist; Collected papers in honour of Jim Allen, pp 372-392. Canberra: Centre for Archaeological Research Australian National University, and Department of Archaeology, Latrobe University. Coombs Academic Publishing, Australian National University.

Intoh, M. 1982. The physical analysis of Pacific pottery. MA thesis. University of Otago.

Kirch, P.V. 1997. The Lapita Peoples: Ancestors of the Oceanic World. Oxford: Blackwell.

Kirch, P.V. 2000. On the Road of the Winds, An Archaeological History of the Pacific Islands before European Contact. Berkeley: University of California Press.

Poulsen, Y. 1987. Early Tongan Prehistory. Canberra: Dept of Prehistory, Australian National University. Terra Australis 12.

Sand, C. 1997. Lapita Collection de poteries du site de Foué. Nouméa: Les Cahiers de l'archaéologie en NouvelleCalédonie, Volume 7.

Sand, C. 1999a. Lapita and non-Lapita ware during New Caledonia's first millennium of Austronesian settlement. In J-C. Galipaud and I. Lilley (eds), Le Pacifique de 5000 à 2000 avant le present, pp.139-159. Paris: Institut de Recherche pour le Développement.

Sand, C. 1999b. Exhibition catalogue, Archaéology des Origines le Lapita Calédonian, New Caledonia, Service des Musées et du Patrimoine de Nouvelle Calédonie.

Siorat, J.P. 1990. A technological analysis of Lapita pottery decoration. In M. Spriggs (ed.), Lapita Design, Form and Composition, pp. 59-82. Canberra: Dept of Prehistory, Australian National University. Occasional Papers in Prehistory 19.

Spriggs, M. 1997. What is Southeast Asian about Lapita? In T. Akazawa and E.J.E. Szathmary (eds), Prehistoric Mongoloid dispersals, pp. 324-348. Oxford: Oxford University Press.

Spriggs, M. 2002. They've grown accustomed to your face. In S. Bedford, C. Sand and D. Burley (eds), Fifty years in the field. Essays in honour and celebration of Richard Shutler Jr's archaeological career, pp. 51-57. Auckland: New Zealand Archaeological Association Monograph 25.

Summerhayes, G. 2000. Recent archaeological investigations in the Bismarck Archipelago, Anir-New Ireland Province, Papua New Guinea. Bulletin of the Indo-Prehistory Association 19:167-174. 